\title{
More placebo use promoted in Germany
}

$\mathrm{P}$ lacebo - the Latin word means "I will please." But some doctors and patients were less than pleased by the German Medical Association's recent announcement about the findings of a major report that concluded that more inactive substances should be used in clinical practice.

Edzard Ernst, a German-born professor of alternative medicine at the University of Exeter, writes in an email that the report is "among the most ridiculous that I have ever read on the subject." It is also at odds with the guidelines of most other countries' medical associations. The American and British authorities, for example, consider the use of placebos without a patient's consent unethical.

The scientific advisory board of the German Medical Association spent more than three years assessing the scientific literature on placebos and compiling it into a report, Placebos in Medicine [Editor's note: report in German] (www.bundesaerztekammer.de/down loads/Placebo_LF_1_17012011.pdf). In launching the report, Christoph Fuchs, managing director of the association, praised the value of such inert pills. "We know today that placebos have a stronger effect and are more complex than previously assumed," he stated in a press release [Editor's note: release in German] (www.bundesaerztekammer .de/downloads/PK_Placebo_Statement _Fuchs1.pdf).

"The placebo effect plays a critical role in every day practice," says Robert Jütte, lead author of the report. Indeed, a survey of German doctors found that half of them had used a placebo before. In the southern German state of Bavaria, the figure was close to $90 \%$. Jütte says that this majority is right: "Every good doctor should have a couple of white or blue sugar pills handy."

Many bioethicists disagree. They see the use of placebos as a violation of the doctor-patient relationship, because it requires the doctor to mislead the patient about his treatment. The British Parlia-

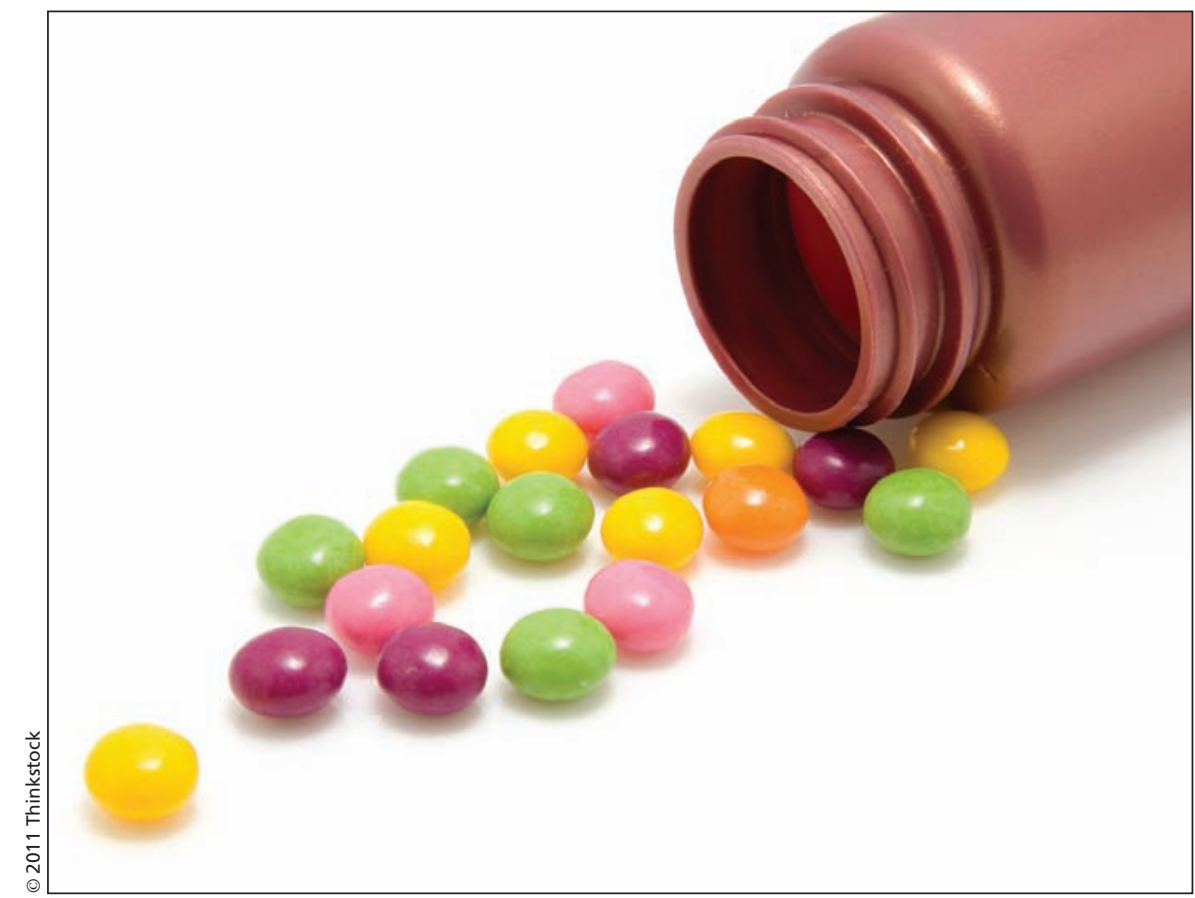

A scientific advisory board in Germany says placebo use is "acceptable" under three circumstances: The patient has a minor condition; no treatment proven to be effective is available; and a placebo treatment seems likely to succeed.

ment's Science and Technology Committee called prescribing pure placebos "bad medicine" (www.parliament.uk/business /committees/committees-archive/science -technology/s-t-homeopathy-inquiry/).

"Their effect is unreliable and unpredictable and cannot form the sole basis of any treatment," the British report adds.

"A call to use more placebos in clinical practice violates the principles of medical ethics," Ernst writes.

In contrast, the scientific advisory board report describes the use of placebo or pseudo-placebo in therapeutic practice as "acceptable," under three circumstances: The patient has a minor condition; no treatment proven to be effective is available; and a placebo treatment seems likely to succeed.

But Ernst writes that "if you look at these conditions closely, one has to ask, whether the authors really see any indication for placebo at all."

The cautious wording of the report was due to a conflict between medical ethics and law, Jütte says. "There are less ethical problems with giving placebos than legal problems. But the laws can change and they should change." Patients with mild depression or pain could be among those benefitting from more placebo use, he adds.

Others are unconvinced.

"There is no data supporting placebo treatment, described to the patient as a pill with no medication, for pain or mild depression," Franklin Miller, member of the senior faculty in the Department of Bioethics at the United States National Institutes of Health and special expert at the US National Institute of Mental Health Intramural Research Program, writes in an email.

Miller views two key issues as relevant to the ethics of recommending placebo treatments in clinical practice.

The first: Is there evidence of clinically significant benefit for patients with the condition in question? He writes in response: "The only condition for which very limited, randomized controlled evidence is available for 
open placebo is irritable bowel syndrome. We need much better data to support the use of placebo pills in clinical practice."

The second issue is even trickier: Can the recommendation be made without deception and be consistent with informed consent?

Jütte suggests that doctors could avoid lying by telling their patients that they are getting a medicine that is not typically administered, but that it might nevertheless help them.

But calling a placebo pill a medicine would still be deceptive, Miller writes. "The ordinary person assumes that when a doctor recommends a medicine there is medication in the pill. This is, of course, not true of 'inert' pills, such as sugar pills."
And while a study on irritable bowel syndrome (PLoS ONE 5(12): e15591 .doi:10.1371/journal.pone.0015591) seems to suggest that some placebo effect is at work even when patients know they are receiving a sugar pill, the study has to be viewed with caution because it has not been independently replicated, argues Ernst. "Even if the results can be confirmed, one must point out that the effect size is so small that the authors admit it is not clinically relevant.'

Indeed, some scientists caution that the placebo effect might be far less powerful than people generally assume. A Cochrane review of studies comparing placebo groups with notreatment groups found little solid evidence of clinically significant benefit for those receiving placebo (Cochrane Database Syst Rev 2010;(1):CD003 974).

The effects commonly seen in placebo groups of randomized controlled trials can be attributable to a host of other unspecific factors such as natural fluctuation in symptoms and regression to the mean. Miller writes that "the inflated view of placebos based on typical placebo-controlled trials stems back to Henry Beecher's classic article, The Powerful Placebo," (JAMA 1955;159:1602-06). "This mistake continues to be made despite the fact that it has been repeatedly criticized," Miller adds. - Kai Kupferschmidt, Berlin, Germany

CMAJ 2011. DOI:10.1503/cmaj.109-3895 